\title{
The arboreal origins of human bipedalism
}

\author{
Susannah K.S. Thorpe ${ }^{1}$, Juliet M. McClymont ${ }^{2} \&$ \\ Robin H. Crompton ${ }^{2}$
}

Almost a century and a half ago, Charles Darwin in The Descent of Man (1871: 141) highlighted the evolution of bipedalism as one of the key features of the human lineage, freeing the hands for carrying and for using and making tools. But how did it arise? The famous footprints from Laetoli in Tanzania show that hominin ancestors were walking upright by at least 3.65 million years ago. Recent work, however, suggests a much earlier origin for bipedalism, in a Miocene primate ancestor that was still predominantly tree-dwelling. Here Susannah Thorpe, Juliet McClymont and Robin Crompton set out the evidence for that hypothesis and reject the notion that the common ancestor of great apes and humans was a knuckle-walking terrestrial species, as are gorillas and chimpanzees today. The article is followed by a series of comments, rounded off by a reply from the authors.

Theories regarding the origins of hominin bipedalism have spent some considerable time 'on the ground' as a result of the knuckle-walking hypothesis, which postulates that our earliest bipedal ancestor evolved from an ape that knuckle-walked on the ground in a way similar to modern chimpanzees or gorillas. By contrast, we argue that there is compelling and unequivocal evidence that bipedalism has arboreal origins.

The concept of an arboreal origin for habitual human bipedalism was first proposed over a century ago. The arboreal behaviour that was considered to be exaptive (i.e. to have 'prepared' the body) for bipedalism has, however, changed fundamentally with the gradual discoveries of new fossil evidence, and with the development of new approaches to reconstructing the ecology and locomotion of extinct species. In particular, study of the ecology and biomechanics of living apes has transformed our understanding of how bipedalism could have evolved. Living apes offer broad models for how the dynamic between habitat and morphology may combine to influence locomotor behaviour. Sir Arthur Keith (1903) was the first to suggest that the arboreal locomotion of apes was important in understanding the process by which upright posture evolved in human ancestors. His studies of primate anatomy and behaviour led to the paradigm that an ape that moved by brachiating (armswinging) underneath branches (suspension) later evolved into a habitual biped (e.g. Morton 1922; Keith 1923). Morphological and locomotor observations continued to be proffered in support of this hypothesis for many decades (see Tuttle 1974 for a review). However,

1 Locomotor Ecology and Biomechanics Laboratory, School of Biosciences, University of Birmingham, Edgbaston, Birmingham B15 2TT, UK (Author for correspondence; Email: s.k.thorpe@bham.ac.uk)

2 Department of Musculoskeletal Biology, Institute of Aging and Chronic Disease, University of Liverpool, Ashton Street, Liverpool L69 3GE, UK 
one of the most important lines of evidence to emerge relatively recently from new fossil discoveries is that adaptations to suspension and arm-swinging must have evolved not once only but convergently, across several millions of years, in multiple fossil ape species (e.g. Almecija et al. 2009).

During the 1970s and ' 80 s, Russell H. Tuttle $(1974,1981)$ proposed that the arboreal ancestor of modern hominins would have been small-bodied-around the size of living gibbons (9-13.5kg) — and would have engaged extensively in vertical climbing (that is, climbing up and down vertical tree trunks with the torso in an upright position), an activity that he considered to be functionally associated with bipedalism. The biomechanical link was defined by Prost (1980) from apparent similarities in the range of joint angles exhibited in vertical climbing by chimpanzees and in human bipedalism, and by Fleagle et al. (1981) from joint movements and muscle activity in these behaviours in New World monkeys. But recent work has undermined this hypothesis by showing that gorillas and orangutans have more extended hip joint angles when moving bipedally than when they are using vertical climbing (Crompton et al. 2003; Watson et al. 2009).

By the early 2000s the fossil record of the Eurasian and East African Miocene (23-5 million years ago (Ma)) was burgeoning and revealing the body form of early 'crown' hominoids ('crown' hominoids being the direct ancestors of all living apes, including humans). These included fossils of species such as Morotopithecus bishopi (from approximately 18-22 Ma), Pierolapithecus catalaunicus (c. $12 \mathrm{Ma}$ ), Hispanopithecus (Dryopithecus) laietanus (c. $10 \mathrm{Ma}$ ) and Orrorin tugenensis $(6 \mathrm{Ma})$. These fossils suggested that, contrary to expectations and fossil evidence from Proconsul hesoloni and associated species, the early crown hominoids stood and moved with an orthograde (upright) posture. Thus features such as their broad, shallow trunks; scapulae positioned on the back rather than side of their bodies, and lumbar vertebral bodies that increased in size towards the lower end of the spine all indicated that these species were frequently upright (MacLatchy 2004; Moyà-Solà et al. 2004; Nakatsukasa et al. 2007; reviewed in Crompton et al. 2008). In addition, since they are estimated to have weighed between 30 and $50 \mathrm{~kg}$, they were also at least as large as adult female great apes (MacLatchy 2004; Moyà-Solà et al. 2004; Nakatsukasa et al. 2007), a finding which casts doubt on the validity of Tuttle's (1981) model of a small-bodied gibbon-like ancestor.

The fact that orthograde (upright) body postures had been evolving and diversifying in our hominoid ancestry for in excess of 15 million years pushed study of the origins of bipedalism back from the Pliocene into the early Miocene. It also challenged the commonly held concept that the acquisition of habitual bipedalism is an appropriate marker of the separation of the hominins from the panins (bonobos and chimpanzees), a separation that is estimated to have occurred only 5-8 million years ago. It pushed the context of bipedal origins back into the forest canopy from the ground (Senut 2011) where it had spent some considerable time as a result of the knuckle-walking hypothesis. This latter paradigm, that has dominated our vision of the evolution of bipedalism since the 1960s, held that because chimpanzees and gorillas move on the ground by quadrupedal horizontal-trunked knuckle-walking, the pre-bipedal ancestor of hominins must also have passed through a terrestrial knuckle-walking phase (e.g. Gebo 1996; Richmond \& Strait 2000). 
In parallel to the burgeoning fossil record, significant progress was being made in quantifying the locomotor ecology of modern wild apes (i.e. the relative proportions of bipedalism and other forms of movement exhibited by a given species in a given setting). Hunt and colleagues (1996) advocated much-needed uniformity in the language used to describe locomotion across primate clades. They wished primarily to avoid the ubiquitous term 'climbing' to describe a wide range of locomotor behaviours that conflated pronograde (horizontal) and orthograde (upright) body postures, and travelling in vertical and horizontal directions. In the event, this has been adhered to more closely by the literature on living primates than that on fossil forms. The significance of the approach was that it allowed comparative quantification of the ecological context of locomotion (how much time a particular species spent in knuckle-walking, brachiating, vertical climbing, etc.; in what kinds of settinge.g. forest canopy, forest floor, open grassland - and an indication of the stresses different behaviours placed on the body). Thus it made it possible to quantify the adaptive advantages of arboreal behaviours, a factor that was lacking from many earlier studies of locomotion that were restricted to studies of captive animals or qualitative observations of wild-living taxa.

The approach revealed that all great apes occasionally choose to engage in arboreal bipedalism-walking along and between branches on two legs (e.g. Hunt 1992; Remis 1995; Thorpe \& Crompton 2005, 2006). It was from this that Hunt (1996) and Stanford (2006) developed the arboreal foraging hypothesis. They showed that in chimpanzees, handassisted bipedal posture (as opposed to bipedal locomotion) was associated with arboreal feeding on relatively stable branches $>100 \mathrm{~mm}$ in diameter, and suggested such behaviour might have been exaptive for terrestrial bipedalism. Postures are, however, less energetically demanding to maintain than locomotion, and standing on large-diameter branches does not pose the safety risks that are associated with balancing on thin, flexible branches. In contrast we studied Sumatran orangutans (Pongo abelii), as they exhibit strong similarity to humans in the extended-leg bipedal kinematics (joint angles) and kinetics (forces exerted on the ground during locomotion) (Crompton et al. 2003; Crompton \& Thorpe 2007). Furthermore, they are the only exclusively arboreal great ape. We found that Sumatran orangutans use extended-leg bipedal locomotion on highly flexible branches, $<40 \mathrm{~mm}$ in diameter (Thorpe et al. 2007a) (Figure 1). This result countered traditional hypotheses that had suggested that movement along flexible branches should be either via orthograde suspension in which the animal gains stability by hanging with its centre of mass directly under the branch; or by 'compliant' quadrupedalism, in which stability is maximised in part by bending the knees and elbows substantially to reduce the movements of the branch caused by the animal's weight.

We also found that in 75 per cent of our observations of orangutan bipedal locomotion along branches, they used their hands for stabilisation, as do chimpanzees (Hunt 1996; Stanford 2006). Hand assistance ensures maximum safety while the bipedalism enables a free hand to reach out for feeding, weight transfer, or balance in the peripheral branches of trees, where the majority of preferred foods are situated and where primates must cross between tree crowns. Being able to access these peripheral branches effectively is highly advantageous because it allows large-bodied apes to cross more gaps between trees. Crossing rather than circumventing gaps in the canopy can dramatically reduce the energy costs of travel, especially where a change of height would otherwise be required (Thorpe et al. 2007b).

(C) Antiquity Publications Ltd. 

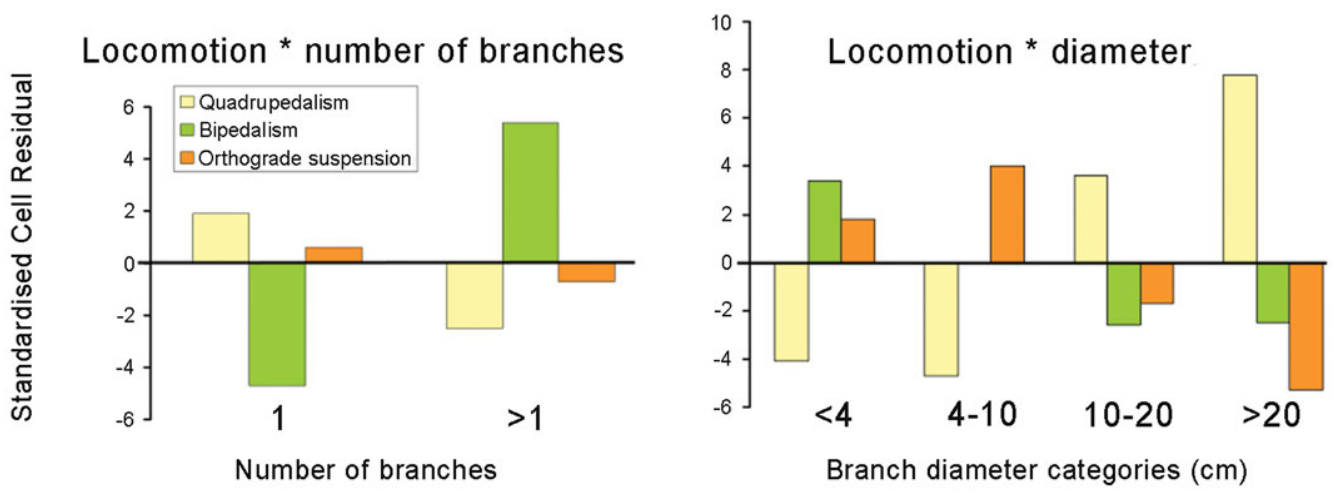

Figure 1. Standardised cell residuals (SCRs) to demonstrate the primary results in the Log linear model of Thorpe et al. 2007a. The left-hand diagram shows the relationship between locomotion and the number of supports used and the right shows the relationship between locomotion and the diameters of the supports used. SCRs indicate by their sign whether an interaction is more (positive values) or less (negative values) common than predicted by the model and, by their size, to what degree. SCRs greater than \pm 2.0 indicate a lack of fit. The graphs show that quadrupedalism is strongly associated with locomotion on single, large, stable supports $>200 \mathrm{~mm}$ in diameter; orthograde suspension is mostly associated with locomotion on supports between 40-100mm in diameter. In contrast bipedalism is strongly associated with locomotion on multiple supports and those that are $<40 \mathrm{~mm}$ in diameter.

We concluded that hand-assisted arboreal bipedalism as part of a smooth continuum of orthograde behaviours ranging from suspending underneath branches to standing on top of them confers a major selective advantage on orangutans and argued that arboreal bipedalism would have been equally advantageous for ancestral crown hominoids (Figure 2).

We are convinced that the accumulating evidence for the arboreal origins of human bipedalism is strong. Inevitably, some do not share our conviction. As part of a more general critique on the use of 'living referential models' to understand fossil taxa, Sayers and Lovejoy (2008) argued that our use of orangutan data was based on false premises. First, they suggested that we studied bipedal posture and not bipedal locomotion. This indicates that they didn't read our paper well; even the title alluded to locomotion rather than posture. They also suggested that orangutans are an unsuitable model because they have feet that are highly specialised for gripping, such as very long toes that cannot therefore have been exaptations for bipedality; and that they are rarely terrestrial, and when they are terrestrial they use knuckle- or fist-walking (citing Tuttle \& Beck 1972). We agree that the feet of orangutans are highly specialised-but even then our recent work (Bates et al. 2013) shows that foot pressures in the bipedalism of orangutans (and bonobos) overlap substantially with those of humans, particularly under the middle of the foot. Nevertheless, orangutan footprint morphology does not need to be exaptive for bipedality for the purposes of our model. We studied Sumatran orangutans because, unlike Bornean orangutans (Pongo pygmaeus sp.) and other great apes, they very rarely descend to the ground and should therefore be a good model for arboreal locomotor ecology. If Sumatran orangutans did (hypothetically) descend to the forest floor they probably would move quadrupedally because palmigrade quadrupedalism is strongly associated with travel on broad, stable tree boughs (Figure 1) (Thorpe \& Crompton 2006; Thorpe et al. 2007a). Furthermore, anecdotal evidence suggests wild Bornean orangutans generally use quadrupedalism when terrestrial. To our knowledge,

(C) Antiquity Publications Ltd. 


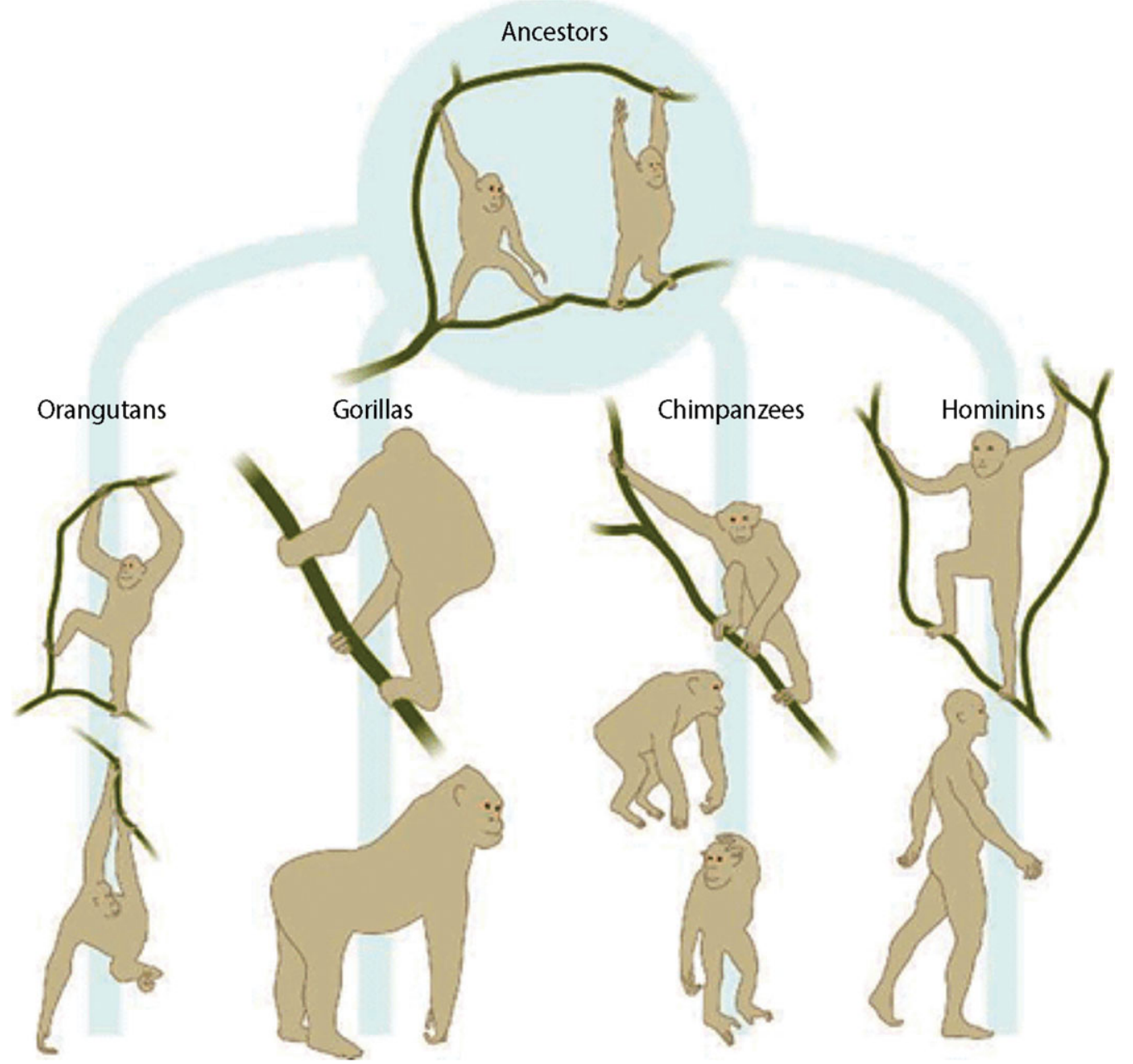

Figure 2. A reconstruction of the arboreal bipedalism hypothesis depicting the evolution of modern great apes including humans from an orthograde ancestral ape, capable of hand-assisted, arboreal bipedalism with extended lower limbs (from O'Higgins \& Elton 2007). Orangutan ancestors became arboreal specialists, whereas the ancestors of gorillas and chimpanzees, in response to changing and variable habitats, climbed vertically in and out of trees, and independently acquired knucklewalking. Hominins retained existing adaptations for extended-limb bipedalism and eventually became committed terrestrial bipeds. Reprinted with permission from $A A A S$.

however, orangutan hand postures in terrestrial locomotion in the wild have never been quantified because hands are difficult to see in the clutter of the forest floor from the distance required for following orangutans in the wild. The hand postures are likely, however, to be something akin to fist-walking simply because of the length of the digits.

The Tuttle and Beck (1972) paper that Sayers and Lovejoy (2008) reference as evidence for orangutans employing knuckle-walking when terrestrial is based primarily on the mostly postural descriptions of the behaviour of a single, captive, very obese male orangutan called Felix. Tuttle and Beck (1972: 33-34) conclude that "although Felix often places his hands in knuckle-walking postures, he rarely supports a major portion of his body weight on (C) Antiquity Publications Ltd. 
knuckle-walking hands". While Sayers and Lovejoy (2008) are entitled to reject the use of referential models, it is then hardly appropriate for them to base their arguments on a referential model based on a single, clearly unhealthy individual whose obesity certainly hampered his locomotor ability. Instead we based our arguments on the behaviours observed in multiple, healthy subjects travelling in a natural habitat.

Overall, Sayers and Lovejoy (2008) fail to grasp the core concepts of our model and perhaps, given their own use of Felix, the concept of referential modelling in general. We suggested that Sumatran orangutans are a useful species to study because they are the only extant great ape to remain in what is generally accepted to be the ancestral great ape nichethe canopy of tropical forest. The value of the model is that Sumatran orangutans employ the behaviour of interest (extended-leg bipedalism) in the appropriate ecological context (the canopy of tropical forest) and therefore can tell us something about that particular behaviour. Whether and how they move on the ground is irrelevant to the model.

Winder et al. (2013) also criticised our theory. They proposed that most of the postcranial/locomotor features of modern hominins are attributable to a single newly identified driver; adaptation for 'complex topographies'. With respect to our study among other so-called 'woodland hypotheses' they claim "an upright climbing adaptation, evolved within the context of tree-dwelling, would not produce all the features required for effective rapid, long-distance terrestrial bipedalism. Explaining how our ancestors survived a locomotor transition in a relatively dangerous semi-open habitat remains a critical challenge to these hypotheses" (Winder et al. 2013: 334). Instead they propose that the acquisition of upright body posture and a broad thorax (chest) (which, currently, can first be identified in the crown hominoid Morotopithecus between 18 and $22 \mathrm{Ma}$ (MacLatchy 2004)), can be explained as an adaptation to 'complex topographies'. So equally are: a) the appearance of a foot with functional lateral and medial arches, and adducted hallux (big toe) (currently first evident in the Laetoli G-1 footprint trail at 3.65 Ma; Day \& Wickens 1980, Crompton et al. 2012); and b) the increase in stature and the shortened upper limb (and the elongated lower limb which seems to accompany it) that are typical of the genus Homo sensu stricto. These features currently first appear between 1.8 and $1.95 \mathrm{Ma}$ in Homo rudolfensis, or in Homo ergaster/Early African Homo erectus at c. $1.6 \mathrm{Ma}$ (reviewed e.g. in Crompton et al. 2008; and Pontzer 2012). It is not at all clear why they consider that exactly the same selective pressure, use of 'complex topographies', would lead to these adaptations in such a piecemeal process over millions of years, rather than all at the same time or in a much tighter and linked time frame. Furthermore, in each case they fail to mention the species under discussion, preferring to use the generic term 'hominins' to describe all stages. Thus, Winder and colleagues are wrong to suggest that explaining how our ancestors survived in an open habitat is a challenge to our hypothesis. We sought to elucidate the origins of bipedal locomotion, which occurred in a very different environment to later refinements for fast bipedal gait in a (mostly) terrestrial setting. The challenge to their hypothesis however is to explain how their theory fits with the fossil record.

The pushing back of bipedal adaptations such as orthograde posture and movement to arboreal early Miocene apes effectively removes the opportunity for a terrestrial knucklewalking stage in the origins of human bipedalism. The only alternative would be to postulate a transition to orthogrady in the crown hominoids (from monkey-like pronogrady in the 


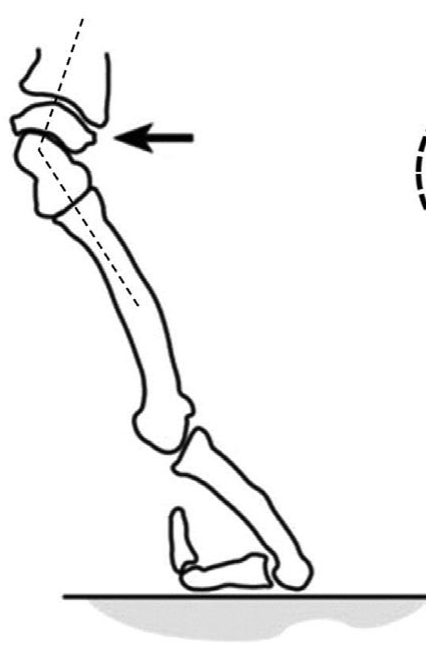

Pan

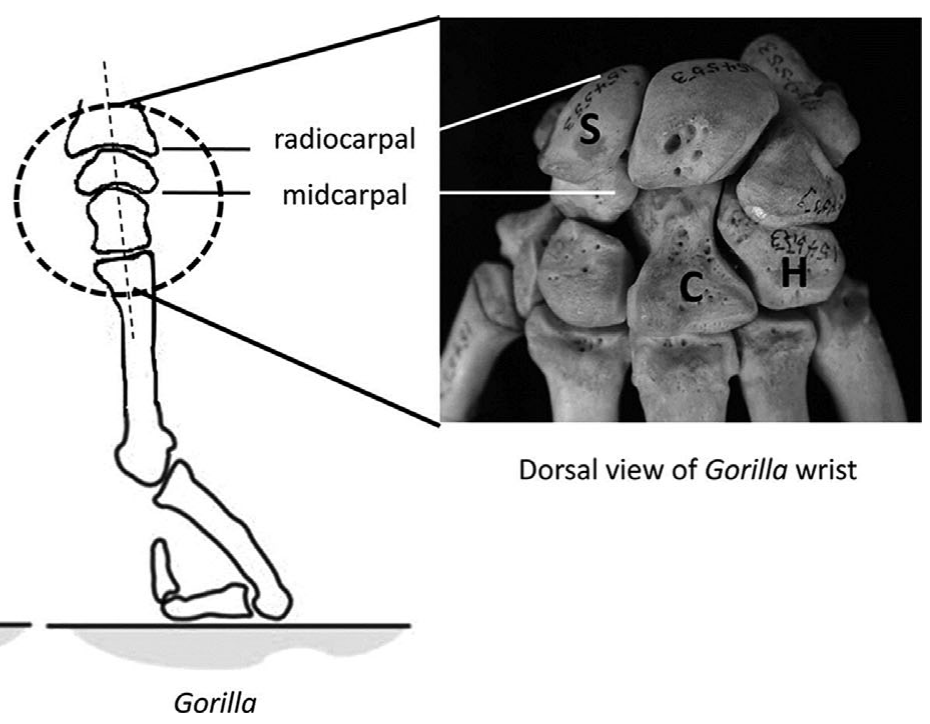

Gorilla

Figure 3. Functional differences in the knuckle-walking hand postures of Pan and Gorilla (from Kivell \& Schmitt 2009). In Pan, the wrist (and carpometacarpal) joints are held in an extended posture (dotted line) such that extension-limiting morphological features are required for stability. In contrast, the authors hypothesise that Gorilla use a columnar, neutral wrist and hand posture with axial loading (dotted line). Radiocarpal and midcarpal joints are labelled in lateral and dorsal views of Gorilla carpus. 'S', scaphoid; 'C,' capitate; 'H,' hamate. (c) The National Academy of Sciences.

common ancestor of the apes and monkeys), back to pronogrady in the African apes and then back again to orthogrady in hominins (Crompton et al. 2008)). Kivell and Schmitt (2009) further undermined the knuckle-walking hypothesis when they tested the extent to which knuckle-walking adaptations were similar in living chimpanzees and gorillas. Not only did they find clear evidence that modes of knuckle-walking in Pan and Gorilla were fundamentally different (Figure 3), they also found what had been claimed to be knucklewalking adaptations in the carpal morphology of a range of non-knuckle-walking monkeys. Of course it is theoretically possible that knuckle-walking did evolve only once in the common ancestor of the African ape and human clade and that these differences evolved after the Gorilla and Pan lineages split (Kivell \& Schmitt 2009). The broad consensus that there is a clear lack of any convincing fossil evidence for knuckle-walking in crown hominoids or early hominins, however, would render it unlikely. Crompton et al. (2010) also pointed out that the hindlimb mechanics of vertical climbing and quadrupedal knuckle-walking are rather similar, involving highly flexed postures of the hip and knee, and suggested that it is in fact these locomotor behaviours that are likely to be functionally and ecologically linked.

It has not been possible to reflect all relevant literature in this short debate piece, nor is it necessary as there are many excellent reviews (e.g. Tuttle 1974; Senut 2011). Rather we have focused on selected highlights of the process by which the scientific world has come to view bipedalism as an ancestral arboreal adaptation rather than a recent terrestrial development. Quantitative studies of the biomechanics and locomotor ecology of wildliving primates have been central to 'fleshing-out' the process by which bipedalism could have been selected for. This does not indicate that extinct species should bear any striking similarity to extant taxa; the Miocene and Pliocene fossil record clearly shows variability (C) Antiquity Publications Ltd. 
in the orthograde and bipedal adaptations of different species. However, analogy to living species facilitates our understanding of the relationship between performance and habitat, which cannot be reconstructed from fossils alone, since the skeleton reflects only a subset of the behaviours that an animal is able to perform. Furthermore, as our own work (Bates et al. 2013) demonstrates for human, bonobo and orangutan feet, distinct morphologies do not necessarily imply qualitatively different functions.

Despite the longevity of the paradigm that derived human bipedalism from chimpanzeelike knuckle-walking, we conclude that the arboreal origin of bipedalism is now overwhelmingly supported by the fossil, biomechanical and ecological evidence. The 50year reign of the knuckle-walking paradigm must be declared over. However, the ancestry of bipedal adaptations; their variability in different species and their piecemeal evolution suggests that their relevance for distinguishing the separation of the hominins from the panins has become substantially blurred.

\section{References}

Almecija, S., D.M. Alba \& S. MoYÀ-SolÀ. 2009. Pierolapithecus and the functional morphology of Miocene ape hand phalanges: paleobiological and evolutionary implications. Journal of Human Evolution 57: 284-97. http://dx.doi.org/ 10.1016/j.jhevol.2009.02.008

Bates, K.T., D. Collins, R. SAVAGE, J.M. McClymont, E. Webster, T.C. Pataky, K. D'Aoút, W.I. Sellers, M.R. BenNetT \& R.H. Crompton. 2013 The evolution of compliance in the human lateral midfoot. Proceedings of the Royal Society B 280: 1818. http://dx.doi.org/10.1098/ rspb.2013.1818

Crompton, R.H. \& S.K.S. Thorpe. 2007. Response to technical comment on "Origin of human bipedalism as an adaptation for locomotion on flexible branches". Science 318: 1066. http://dx.doi.org/10.1126/science. 1146580

Crompton, R.H., Y. Li, S.K.S. Thorpe, W.J. WanG, R. Savage, R. Payne, T.C. Carey, P. Aerts, L. Van Elsacker, A. Hofstetter, M.M. Gunther, K. D’Août \& D. DeClerq. 2003. The biomechanical evolution of erect bipedality. Courier Forschungsinstitut Senckenberg 243: 135-46.

Crompton, R.H., E. Vereeke \& S.K.S. Thorpe. 2008. Locomotion and posture from the common hominoid ancestor to fully modern hominins, with special reference to the last common panin/hominin ancestor. Journal of Anatomy 212: 501-43. http:// dx.doi.org/10.1111/j.1469-7580.2008.00870.x

Crompton, R.H., W.I. Sellers \& S.K.S. Thorpe. 2010. Arborealism, terrestrialism and bipedalism. Philosophical Transactions of the Royal Society B 365: 3301-14. http://dx.doi.org/10.1098/ rstb.2010.0035
Crompton, R.H., T.C. Pataky, R. SaVage, K. D’Aoút, M.R. BennetT, M.H. DAY, S. Morse \& W.I. SELLERS. 2012. Human-like external function of the foot, and fully upright gait, confirmed in the 3.66 million year old Laetoli hominin footprints by topographic statistics, experimental footprint-formation and computer simulation. Journal of the Royal Society Interface 9: 707-19. http://dx.doi.org/10.1098/rsif.2011.0258

DARWIN, C.R. 1871. The descent of man, and selection in relation to sex. Volume 1. London: John Murray.

DAY, M.H. \& E.H. WICKENS. 1980. Laetoli Pliocene hominid footprints and bipedalism. Nature 286: 385-87. http://dx.doi.org/10.1038/286385a0

Fleagle, J.G., J.T. STERN, W.L. JungERS, R.L. Susman, A.K. VANGOR \& J.P. Wells. 1981. Climbing: a biomechanical link with brachiation and with bipedalism. Symposium of the Zoological Society of London 48: 359-75.

GeBO, D.L. 1996. Climbing, brachiation, and terrestrial quadrupedalism: historical precursors of hominid bipedalism. American Journal of Physical Anthropology 101: 55-92. http://dx.doi.org/ 10.1002/(SICI)1096-8644(199609) 101:1<55:: AID-AJPA5>3.0.CO;2-C

HunT, K.D. 1992. Positional behavior of Pan troglodytes in the Mahale Mountains and Gombe Stream National Parks, Tanzania. American Journal of Physical Anthropology 87: 83-105. http://dx.doi.org/10.1002/ajpa.1330870108

- 1996. The postural feeding hypothesis: an ecological model for the evolution of bipedalism. South African Journal of Science 92: 77-90.

Hunt, K.D., J.G.H. Cant, D.L. Gebo, M.D. Rose, S.E. Walker \& D. Youlatos. 1996. Standardized descriptions of primate locomotor and postural modes. Primates 37: 363-87. 
KeITH, A. 1903. The extent to which the posterior segments of the body have been transmuted and suppressed in the evolution of man and allied primates. Journal of Anatomy and Physiology 37: 18-40. http://dx.doi.org/10.1007/BF02381373

- 1923. Man's posture: its evolution and disorders. British Medical Journal 1: 451-672. http://dx.doi.org/10.1136/bmj.1.3246.451

KIVELL, T.L. \& D. SCHMITT. 2009. Independent evolution of knuckle-walking in African apes shows that humans did not evolve from a knuckle-walking ancestor. Proceedings of the National Academy of Sciences of the USA 106: 14241-46. http://dx.doi.org/10.1073/pnas.0901280106

MaCLATCHY, L. 2004. The oldest ape. Evolutionary Anthropology 13: 90-103. http://dx.doi.org/ 10.1002/evan.10133

MORTON, D.J. 1922. Evolution of the human foot - I. American Journal of Physical Anthropology 5: 305-36. http://dx.doi.org/10.1002/ ajpa.1330050409

MoYÀ-SOlÀ, S., M. KÖHLER, D.M. Alba, I. Casanovas-Vilar \& J. GaLindo. 2004 Pierolapithecus catalaunicus, a new Middle Miocene great ape from Spain. Science 306: 1339-44. http://dx.doi.org/10.1126/science.1103094

Nakatsukasa, M., M. PickFord, N. Egi \& B. SENut. 2007. Femur length, body mass and stature estimates of Orrorin tugenensis, a 6 Ma hominid from Kenya. Primates 48: 171-78. http://dx.doi.org/10.1007/s10329-007-0040-7

O’Higgins, P. \& S. ELTON. 2007. Walking on trees. Science 316: 1292-94. http://dx.doi.org/ 10.1126/science. 1143571

Pontzer, H. 2012. Ecological energetics in early Homo. Current Anthropology 53: S346-58. http://dx.doi.org/10.1086/667402

Prost, J.H. 1980. Origin of bipedalism. American Journal of Physical Anthropology 52: 175-98. http://dx.doi.org/10.1002/ajpa.1330520204

REMIS, M. 1995. Effects of body size and social context on the arboreal activities of lowland gorillas in the Central African Republic. American Journal of Physical Anthropology 97: 413-33. http://dx.doi.org/10.1002/ajpa.1330970408

RichMOND, B.G. \& D.S. STRAIT. 2000. Evidence that humans evolved from a knuckle-walking ancestor. Nature 404: 382-85. http://dx.doi. org/10.1038/35006045
SAYERS, K. \& C.O. Lovejoy. 2008. The chimpanzee has no clothes. Current Anthropology 49: 87-114. http://dx.doi.org/10.1086/523675

SENUT, B. 2011. Fifty years of debate on the origins of human bipedalism. Journal of Biological Research 84: 37-46.

STANFORD, C.B. 2006. Arboreal bipedalism in wild chimpanzees: implications for the evolution of hominid posture and locomotion. American Journal of Physical Anthropology 129: 225-31. http://dx.doi.org/10.1002/ajpa.20284

ThORPE, S.K.S. \& R.H. CromPTON. 2005. Locomotor ecology of wild orangutans (Pongo abelii) in the Gunung Leuser Ecosystem, Sumatra, Indonesia: a multivariate analysis using log-linear modelling. American Journal of Physical Anthropology 127: 58-78. http://dx.doi.org/10.1002/ajpa.20151

- 2006. Orangutan positional behavior and the nature of arboreal locomotion in Hominoidea. American Journal of Physical Anthropology 131: 384-401. http://dx.doi.org/10.1002/ajpa.20422

ThOrPe, S.K.S., R. Holder \& R.H. Crompton. 2007a. Origin of human bipedalism as an adaptation for locomotion on flexible branches. Science 316: 1328-31. http://dx.doi.org/ $10.1126 /$ science. 1140799

Thorpe, S.K.S., R.H. Crompton \& R.McN. AlEXANDER. 2007b. Orangutans utilise compliant branches to lower the energetic cost of locomotion. Biology Letters 3: 253-56. http://dx.doi.org/ 10.1098/rsbl.2007.0049

TutTle, R.H. 1974. Darwin's apes, dental apes and the descent of man. Current Anthropology 15: 389-426. http://dx.doi.org/10.1086/201494

- 1981. Evolution of hominid bipedalism and prehensile capabilities. Philosophical Transactions of the Royal Society of London B 292: 89-94. http://dx.doi.org/10.1098/rstb.1981.0016

TutTle, R.H. \& B.B. BECK. 1972. Knuckle walking hand postures in an orangutan (Pongo pygmaeus). Nature 236: 33-34. http://dx.doi. org/10.1038/236033a0

Watson, J.C., R. Payne, A.C. Chamberlain, R. Jones $\&$ W.I. SELLERS. 2009. The kinematics of load carrying in humans and great apes: implications for the evolution of human bipedalism. Folia Primatologia 80: 309-28. http://dx.doi.org/10.1159/000258646

Winder, I.C., G.C.P. KING, M. Devès \& G.N. BAILEY. 2013. Complex topography and human evolution: the missing link. Antiquity 87: 333-49.

(C) Antiquity Publications Ltd. 